\title{
Persistent Truncus Arteriosus With Intact Ventricular Septum: Clinical, Hemodynamic and Short-term Surgical Outcome
}

\author{
Gholamhossein Ajami, ${ }^{1}$ Ahmad Ali Amirghofran, ${ }^{2}$ Hamid Amoozgar, ${ }^{1,3}$ and Mohammad Borzouee \\ ${ }^{1}$ Cardiovascular and Neonatology Research Center, Shiraz University of Medical Sciences, Shiraz, IR Iran \\ ${ }^{2}$ Cardiothoracic Surgery Unit, Shiraz University of Medical Sciences, Shiraz, IR Iran \\ ${ }^{3}$ Department of Pediatrics, Namazi Hospital, Shiraz, IR Iran \\ *Corresponding author: Hamid Amoozgar, Department of Pediatrics, Namazi Hospital, P. O. Box: 7193711351, Shiraz, IR Iran. Tel:+98-9173111877, Fax: +98-7136474298, E-mail: amozgah@sums.ac.ir
}

Received: June 23, 2015; Revised: July 10, 2015; Accepted: August 7, 2015

Introduction: Truncus arteriosus with intact ventricular septum is a rare and unique variant of persistent truncus arteriosus (PTA) which usually presents with central cyanosis and congestive heart failure in neonate and early infancy. Associated cardiac and non-cardiac anomalies may affect morbidity and mortality of these patients.

Case Presentation: We describe clinical presentation, echocardiography and angiographic features of a 7-month old boy with PTA and intact ventricular septum who underwent surgical repair of the anomaly at our institution. Operative findings, surgical procedure and short-term outcome are reported.

Conclusions: While our patient had systemic pulmonary arterial pressure at the time of complete surgical repair, it was improved after surgery.

Keywords: Truncus Arteriosus; Persistent; Intact Ventricular Septum; Outcome

\section{Introduction}

PTA, best defined as a cardiac defect, in which a single arterial trunk arises through a single semilunar valve from the base of the heart and supplies the coronary arteries, one or both pulmonary arteries and the aorta (1).

Collet and Edward (2) classified PTA in 4 major types based on an embryonic theory. In their classification, based on observation in 116 cases, presence of a ventricular septal defect (VSD) was considered as one of the major components of this congenital heart disease. In 1965 van Praagh (3), evaluating a series of necropsy and literature findings expanded the classification system considering associated abnormalities of great arteries. Accordingly, they divided PTA into two basic types: type A, with VSD and type B, without VSD, the latter being a very rare variant. Each type is further classified according to the origin and the source of pulmonary blood supply and aortic arch abnormalities. We describe clinical presentation, echocardiography and angiographic features of a boy with PTA and intact ventricular septum who underwent surgical repair of the anomaly at our institution. Operative findings, surgical procedure and short-term outcome are reported.

\section{Case Presentation}

A 25 days old boy was admitted to the neonatal intensive care unit of Nemazee Hospital of Shiraz University of Medical Sciences, Shiraz, due to respiratory distress and mild central cyanosis. A cardiac murmur was detected on out-patient visit. Respiratory rate was 70/minute, pulse rate $147 / \mathrm{minute}$ and $\mathrm{BP} 80 / 35 \mathrm{mmHg}$. Pulse was bounding, pericardium active with a single loud P2, and grade 3/6 ejection systolic murmur heard best at apex and left sternal border.

A chest X-ray revealed cardiomegaly with increased vascular markings (Figure 1). Electrocardiogram showed normal sinus rhythm with right QRS axis deviation and biventricular hypertrophy.

Echocardiographic studies revealed situs solitus, intact interatrial septum with normal systemic and pulmonary venous connections. Intact interventricular septum with normal mitral valve and tricuspid valve demonstrated by two dimentional, color mapping and pulsed Doppler studies (Figure $2 \mathrm{~A}$ ).

A single arterial trunk with 4 thick leaflets originated from both ventricles with straddling ventricular septum (Figure $2 \mathrm{~B}$ ). A gradient of about $44 \mathrm{mmHg}$ measured by continuous wave Doppler was detected between left ventricle and arterial trunk (Figure $2 \mathrm{C}$ ). Anti-failure therapy started while the patient was on waiting list for surgery. At 7 months of age with possibility of large aorta-pulmonary window versus PTA type B1, cardiac catheterization and angiography was performed. There was a 50 mmHg gradient between left ventricle and arterial trunk.

Copyright (C) 2015, Growth \& Development Research Center. This is an open-access article distributed under the terms of the Creative Commons Attribution-NonCommercial 4.0 International License (http://creativecommons.org/licenses/by-nc/4.0/) which permits copy and redistribute the material just in noncommercial usages, provided the original work is properly cited. 


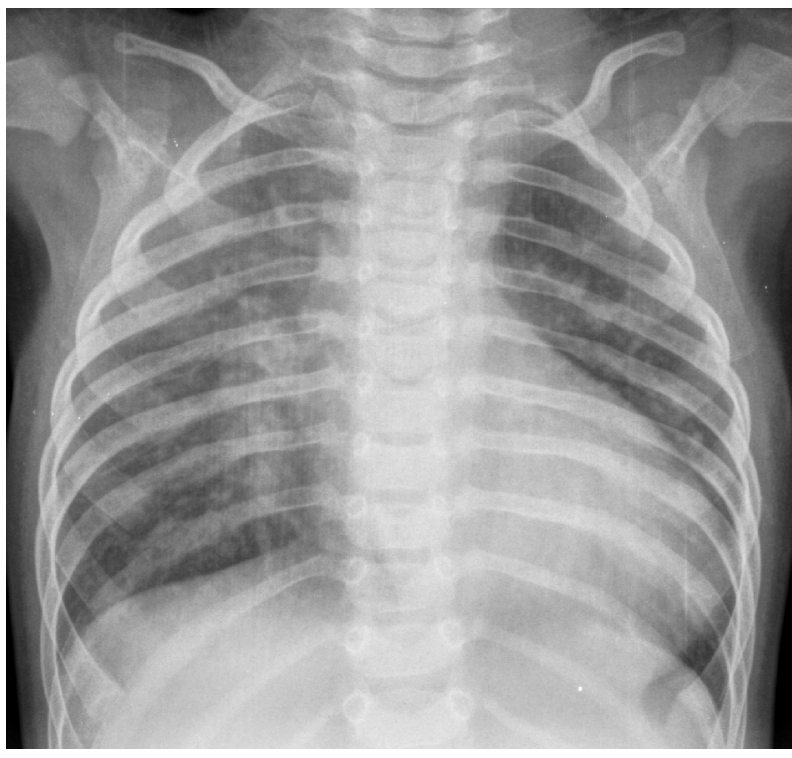

Figure 1. Anteroposterior Projection of Chest X-Ray Revealed Cardiomeg aly With Increased Vascular Markings
Left and right ventricular angiogram revealed intact ventricular septum (Figure $3 \mathrm{~A}$ ). Arterial trunk angiogram on anterior-posterior view and lateral projections showed opacification of the coronaries, pulmonary arteries and aortic arch (Figure $3 \mathrm{~B}$ ).

Operative findings revealed a single arterial trunk emerging from both ventricles which over-rided an intact interventricular septum (Figure $4 \mathrm{~A}$ ). The truncal valve was tricuspid. The septal crest was attached to the inferior aspect of one cusp and stretching the confronting commissure by a thick fibrotic raphe dividing the valve into two separate orifices right in the midpart, giving rise to almost one and a half leaflets in each side. There was some fibrous web below the valve in the left side which was resected. The connection of the right ventricular outflow tract to this valve and the trunk was closed by a Gortex patch through the valve. The cusps were left as they were in both sides. The routine repair of the truncus arteriosus was continued by connecting the right ventriculotomy to the main pulmonary artery which was resected from the posterior aspect of the trunk via a $17 \mathrm{~mm}$ aortic homograft. The aortic defect was repaired by bovine pericardial patch and the transected aorta reconnected. The patient tolerated the procedure well. He was extubated after 20 hours and discharged on the tenth day of hospitalization.

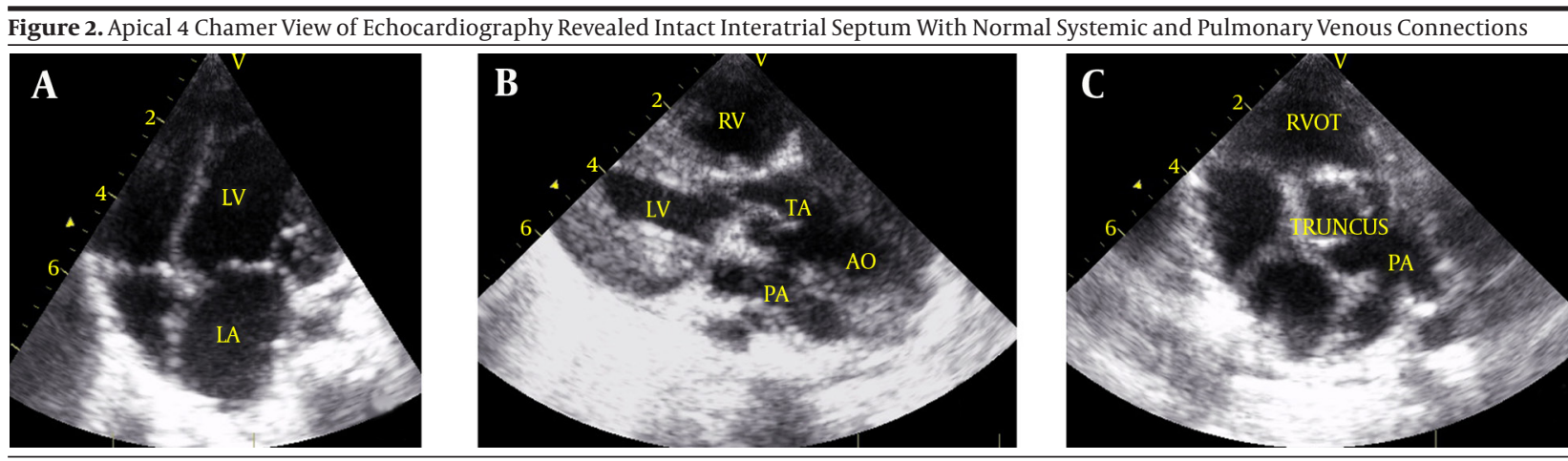

Intact interventricular septum with normal mitral valve and tricuspid valve (a), a single arterial trunk with 4 thick leaflets originated from both ventricles (b), the trunk supplied coronary arteries, pulmonary artery and its branches and continued as left aortic arch and branches (c).

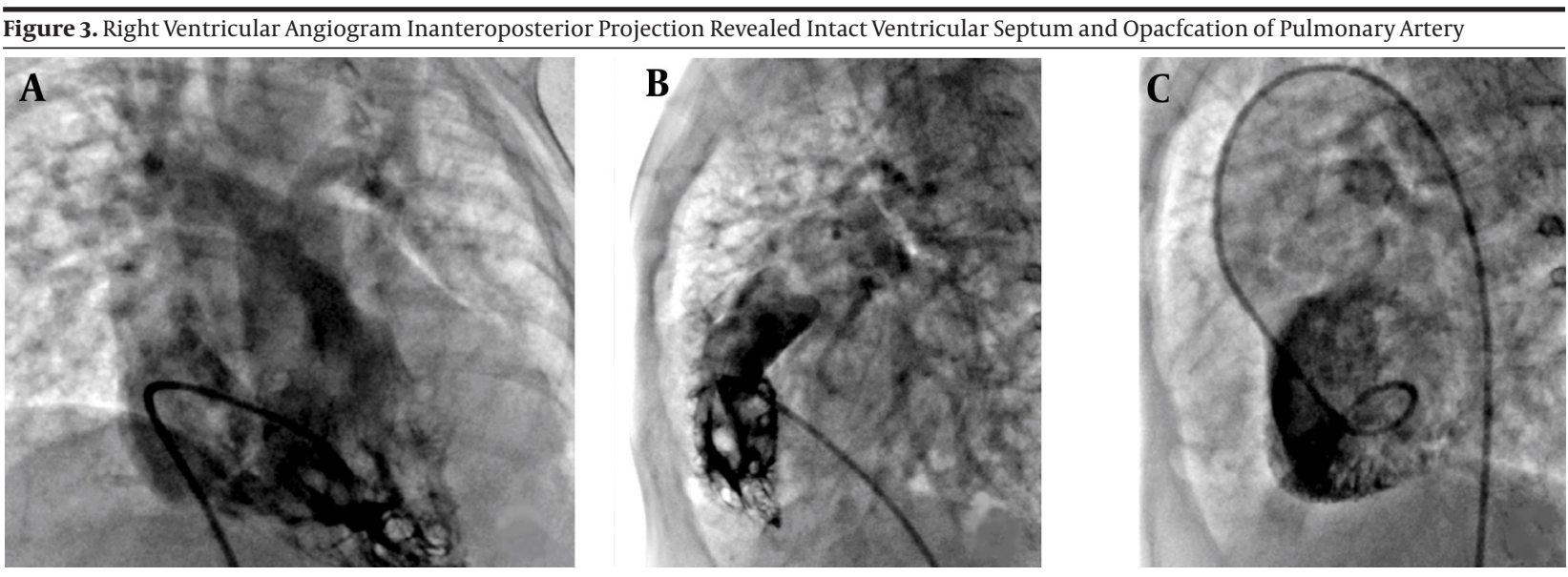

(a), Right ventricular angiogram on lateral projections showed opacification pulmonary arteries and intact ventricular septum (b), left ventricular angiogram on lateral projections showed opacification aorta and intact ventricular septum (c). 


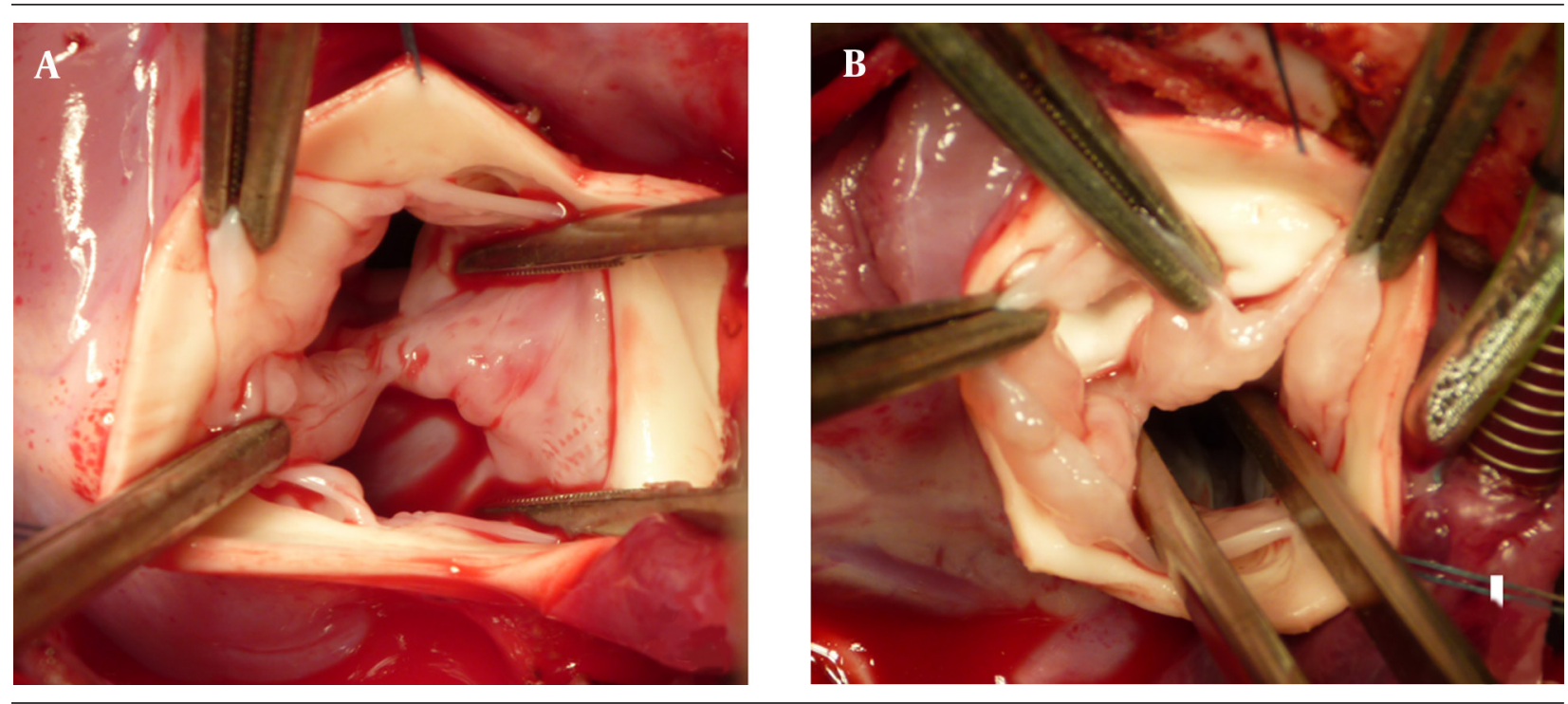

(a), Truncal valve was tricuspid and a thick raphe connected one and half leaflets on each side (b).

Post-operative echocardiography 1 week after surgical repair revealed acceptable ejection fraction (64\%) with mild pulmonary insufficiency and mean pulmonary artery pressure of $64 \mathrm{mmHg}$ and diastolic pressure of 45 mmHg. On the follow-up 4 months later, the degree of homograft insufficiency was reduced to trivial and mean pulmonary artery pressure was decreased to about 18 $\mathrm{mmHg}$ while the patient received sildenafil to control pulmonary arterial hypertension.

\section{Discussion}

The overall survival and surgical outcome of the patients with PTA has much improved since 1965 when the complete repair of this defect was reported by McGoon et al. (4). The most important non cardiac abnormality in these patients is micro deletion of chromosome $22 \mathrm{q} 11.2$ which is frequently seen in those who have conotruncal defects including patients with PTA (5). Although, we could not perform cytogenetic studies, our patient was not syndromic and received routine vaccinations including BCG vaccine without any complication. Although the number of reported cases of PTA type B is limited in literature, there has been a high rate of associated cardiac anomalies among these patients such as hypoplastic left ventricle, hypoplastic right ventricle or truncal valve malfunctioning. Very often these patients were considered inoperable (6-10).

Our patient, a 7-month old boy with type B1, tolerated the complete surgical repair after release of left ventricle outflow tract obstruction and use of a homograft for right ventricle outflow tract reconstruction while having systemic pulmonary arterial pressure. Juaneda et al. have reported the pattern of pulmonary vascular damage in children with PTA, based on quantitative, morphometric techniques in the lung biopsy and/or postmortem studies (11). Their study showed that structural pulmonary abnormalities may potentially be reversible even in infants with pulmonary vascular resistance $\geq 8$ units $/ \mathrm{m}^{2}$. They concluded that beyond the first year of life the pulmonary vascular disease may progress despite successful surgical repair. While our patient had systemic pulmonary arterial pressure at the time of complete surgical repair, 4 months later the pulmonary pressure was normal, although she was on sildenafil $0.5 \mathrm{mg} / \mathrm{kg}$ per dose 3 times a day.

Long-term follow-up of the patients with repaired PTA have demonstrated the need for surgical or catheter based reintervention, especially for right ventricular outflow tract obstruction or truncal valve dysfunction (12). Therefore, on long-term follow-up our patient needs close monitoring for functional status, pulmonary arterial pressure, inevitable homograft replacement or revision and regular assessment of function of neoaorta.

\section{References}

1. Crupi G, Macartney FJ, Anderson RH. Persistent truncus arteriosus. A study of 66 autopsy cases with special reference to definition and morphogenesis. Am J Cardiol. 1977;40(4):569-78.

2. Collett RW, Edwards JE. Persistent truncus arteriosus; a classification according to anatomic types. Surg Clin North Am. 1949;29(4):1245-70.

3. Van Praagh R, Van Praagh S. The anatomy of common aorticopulmonary trunk (truncus arteriosus communis) and its embryologic implications. A study of 57 necropsy cases. Am JCardiol. 1965;16(3):406-25.

4. McGoon DC, Rastelli GC, Ongley PA. An operation for the correction of truncus arteriosus. JAMA. 1968;205(2):69-73.

5. Digilio M, Marino B, Capolino R, Dallapiccola B. Clinical manifestations of Deletion 22q11.2 syndrome (DiGeorge/Velo-CardioFacial syndrome). Images Paediatr Cardiol. 2005;7(2):23-34.

6. Alves PM, Ferrari AH. Common arterial trunk arising exclusively from the right ventricle with hypoplastic left ventricle and intact ventricular septum. Int J Cardiol. 1987;16(1):99-102. 


\section{Ajami G et al.}

7. Bhardwar V, Singh J, Malhotra V, Singh P. Rare Variant of Truncus Arteriosus with Intact Ventricular Septum and Hypoplastic Left Heart - A Case Report. Indian J Forensic Med Toxicol. 2013;7(2):179-81.

8. Murdison KA, McLean DA, Carpenter B, Duncan WJ. Truncus arteriosus communis associated with mitral valve and left ventricular hypoplasia without ventricular septal defect: unique combination. Pediatr Cardiol. 1996;17(5):322-6.

9. Zeevi B, Dembo L, Berant M. Rare variant of truncus arteriosus with intact ventricular septum and hypoplastic right ventricle.
Br Heart J. 1992;68(2):214-5.

10. Zhang YQ, Shen R, Sun K, Zhong SW, Wu YR. Persistent truncus arteriosus with intact ventricular septum diagnosed by echocardiography. Chin Med J (Engl). 2009;122(22):2798-800.

11. Juaneda E, Haworth SG. Pulmonary vascular disease in children with truncus arteriosus. Am J Cardiol. 1984;54(10):1314-20.

12. Vohra HA, Whistance RN, Chia AX, Janusauskas V, Nikolaidis N, Roubelakis A, et al. Long-term follow-up after primary complete repair of common arterial trunk with homograft: a 40-year experience.J Thorac Cardiovasc Surg. 2010;140(2):325-9. 